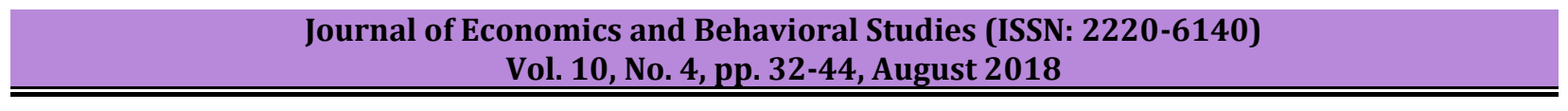

\title{
Determinants of Eastern Cape Gross Fixed Capital Formation and Its Impact on the South African Economic Performance
}

\author{
Bhasela Yalezo, Bokana G. K \\ University of KwaZulu-Natal, Westville, South Africa \\ yalezob@ukzn.ac.za, bokanakg@ukzn.ac.za
}

\begin{abstract}
This study aimed at investigating the factors that determine gross fixed capital formation in the Eastern Cape province of South Africa using time series autoregressive distributive lags (ARDL) on a data covering 1996-2015. We are constraint with the time length of the data because the range of time falls within the period when South Africa got her independence and actually the reliability of most data for most economic activities began after independence. The analyses carried out in this study are basically from two study dimensions. Firstly, we investigated which factors determine the growth of Eastern Cape Gross fixed capital formation and the classification of all economic activity into primary, secondary and tertiary sectors enabled us to identify the significant role of tertiary sector among others in analyzing which factors determine Easter Cape gross fixed capital formation. Again, growth is enhanced through the following determinants: Catering and Accommodation (TF17) and not necessarily when Wholesale and retail trade is inclusive; Again, there is a better performance of the GFCF in the tertiary sector with Communication (TG19) than when Transport and storage are merged together, and finally, Business services (TH21) behaves better with tertiary sector than when it combines with Finance, Insurance and real estate. Hence, for policy implication, the growth of primary and secondary should be considered urgent and should be given ultimate policy consideration as it appears that these sections contribute very negligibly to the growth of Eastern Cape gross fixed capital formation.
\end{abstract}

\section{Keywords: Gross fixed capital formation, Eastern Cape, ARDL, Economic Growth}

\section{Introduction}

Economic theory has established that economic activity resulting in high saving rates, together with high levels of capital formation are preconditions for sustained economic growth in any given economy. This is because to finance high levels of capital formation, the high level of savings are required for an increased high level of productivity and consequently long-term growth in the economy. To finance capital formation, nations can hardly totally be dependent on foreign investment (Akinola, and Omolade, 2013). Capital formation is an integral aspect of the gross domestic product and this concept emphasized that society does not concentrate the whole part of her current production output to the immediate consumption needs but rather keeps a proportional part of it for the creation of capital goods. Capital formation enhances production, hence it determines the speed of economic growth in any country (Jhingan, 2005). In the recent time, South Africa chose privatization policies as an alternative option, with the aims to stimulate, to enhance and to foster faster improvement in the propensity to invest in the form of capital formation among the various levels of citizens, real sectors and the government of the country.

The result of this Privatization policies lead to efficiency in the allocation of economic resources, expectations of efficiency, reduce unemployment, maintain a low inflation rate and increase in aggregate supply (Karim et al., 2010). The process of development that could be traced in other to achieve the expected capital formation are these interrelated conditions: availability of financial institution to manage the channelled of funds, availability of investible fund for savings while investing the return of savings into capital goods (Jhinghan, 2003). Hence, capital formation is a concept that identified investment as the part of current income that is not consumed but rather invested in returns for future real incomes (Bakare, 2011). Capital formation could impact on the country's economy as it helps the citizens to improve and maintain general standards of living. Adopting Mathematical approach, it attempts to weigh the value of currently purchased or existing assets (fixed) by the government, businesses, and households and this process involves the acquisition of productive capital goods. The need for this study came from the concern to determine the possible contribution of Eastern Cape to the Investment target policy of the current government. 
The study is interested in viewing the various sectors of GFCF in Eastern Cape from the perspective of their overall impact on South African Economic growth, and if South Africa as a nation would need to meet her economic development objectives, of great importance is the need for capital formation or capital accumulation otherwise known as physical capital stock. This is because South African economic development could only be measured effectively through the building of capital equipment on a sufficient scale to increase productivity in mining, agriculture, plantations and industry in a large quantity sufficient enough to move the economies to the targeted level. Of course, capital accumulation is required to construct hospitals, schools, railways, roads, standards of living, hence the study's hypothesis is that there is no significant sectorial impact of Eastern Cape economic activity on the Eastern Cape Gross Fixed Capital Formation. The objectives of the paper are: To examine the Eastern Cape sectorial activity and their impacts on the overall Eastern Cape gross fixed capital formation. To analyze which of the sectors contribute to Eastern Cape gross fixed capital formation.

\section{Literature Review}

The following theories are applied for this study to showcase the behavioural investment features among government, firms and organisations in the Eastern Cape Province of South Africa. According to the HarrodDomar model, when investment is stimulated, it would lead to more economic growth in the economy. Therefore, for a nation to invest more in capital formation, it would be expected that the economies save sizeable part of its resources from the current consumption, since savings simply means diverting a certain proportion of its current consumption. Bakare (2011) argued that a given economy should save a reasonable proportion of her national income in other to replace a worn out capital good, However, Pettinger (2014) opined that improving saving ratio would not be appropriate in an era where getting food for the people places a big concern to the government, therefore improving the ratios of saving in developing economies is most difficult to achieve. Certain factors such as levels of corruption, labour productivity and technological innovation were ignored in the Harrod-Domar model.

Investment in the Neo-Classical approach takes another dimension as it addresses the objective to remove the Harrod-Domar model shortcomings. According to the neoclassical approach, the rental cost of capital and the level of output are the important factors that determine capital stock (Uremadu, 2012). In 1968, Tobin Q investment theory allowed the cost of capital to determine the growth of the economy and therefore argued that investments could still be achieved provided the market value and the book value remain unequal (Kanu, and Ozurumba, 2014). Again, from the Marginal efficiency of capital hypothesis, the value of capital compared to the interest rate determines the level of investment in a given economy (Kanu, and Ozurumba, 2014) and therefore, investment should be discouraged provided the marginal rate of capital is lesser than interest rate, otherwise, investments should be increased. The rate of interest and rate of return over cost in any direction, determine the level of investment (Fisher, 1930).

Empirical Literature: In this paper, various aspects of the relationship connecting economic growth and capital formation have been reviewed. Under Some reviewed studies, ordinary least squares (OLS) were employed together with Vector Error Correction Model (VECM) to show the significant contribution of capital formation on economic growth as conducted by Bakare (2011) who examined the relationship between capital formation and growth in Nigeria. Rajni (2013) studied the causal effects among imports, exports, and Indian capital formation, the study was conducted by adopting a test on Granger causality. The collected data was from the economic survey and handbook of India. He discovered from his findings that there is a bidirectional causal relationship between export growth and gross domestic capital formation whereas there was an existence of unidirectional causal effects among import, capital formation and export emanating from the test on Granger causality. Malawi (2005) investigated the gross fixed capital formation trends and its impacts on money supply and economic performance in Algeria during the time period of 1971 and 2003. Granger- causality test was the adopted method to decompose the variance, and consequently the impulse response functions. The result indicates that all the variables, namely money supply and fixed capital formation can boost economic growth according to the Granger test. Ugochukwu and Chinyere (2013) for instance, analyzed the effects of capital formation on economic growth in Nigeria. Their findings indicated that capital formation is significantly and positively contributes to economic growth in Nigeria. 
According to Ncanywa and Makhenyane (2016), some studies have shown in the recent years that the role of capital formation economy among the developing countries is of great importance to economic growth (Ghura, and Hadji, 1996; Ghura, 1997; Beddies, 1999; Kumo, 2012; Ugochukwu, and Chinyere, 2013). It has been verified, that the increase in the economic growth, is associated to flow with an increase in capital formation in Nigeria (Ugochukwu, and Chinyere, 2013; Adegboyega, and Odusanya, 2014; Muneer et al., 2016). Pathunia (2013) argued that there is a connection between exports growth and capital formation in a given economy. Hence, through the activities inherent in capital formation, a nation could improve its tangible capital stock as it injects more fund in the economic infrastructure and social and consequently impact on economic growth. Karim (2010) however, noted that there is no significant long-run relationship between economic growth and net investments in Malaysia. There is a gradual improvement in the gross fixed capital formation moving from 73065 ZAR Million in 1962 to 624408 ZAR Million in last quarter of 2014 according to South Africa experienced (Stats SA, 2015).

This could be the result of South African adherence to the movement towards privatization policies' adoption, as the country tries to stimulate the growth in the capital formation (Perkins et al., 2005). The original aim is to increase aggregate supply, allocate economic resources efficiently, maintain a low inflation rate and reduce unemployment. From the contradicting results indicated by scholars so far, together with the trends exhibited by the South Africa gross fixed capital formation (GFCF) over the years, it is interesting to investigate which factors determine the increase in the Eastern Cape GFCF. In addition, capital formation exhibited positive effects on the stock market, whereas it negatively contributes to inflation and rates interest (Ugochukwu, and Chinyere, 2013; Khan et al., 2013). The most remarkable conclusion was that Nigeria's capital formation accumulation could boost the economy in the long run and develop the real state of the economy. Shuaib and Dania (2015) also argued that there is a significant relationship between growth and gross domestic capital formation in Nigeria. Adegboyga and Odusanga (2014) examined the relationship among trade openness, Foreign Direct Interest, gross fixed capital formation and growth in the Nigerian economy, they also found a positive association-ship when time series data were adopted.

Based on the result of Adegboyga \& Odusanga (2014) the findings showed that capital formation could positively impact on the growth of the economy. They further suggested that Nigeria needs to increase the quality of its monetary and fiscal policies to promote her exports which would finally impact on her economic growth. They further recommended that the government of Nigeria must consider the framework within the institutional setting since there is a positive but insignificance volume of Foreign Direct Investment on economic growth. Kanu and Ozurumba (2014) also examined the contributing effects of capital formation on the Nigerian economic growth through the adoption of techniques in the multiple regression. The study adopted economic growth, gross fixed capital formation, total imports, total exports, inflation and total savings as her main variables. Findings revealed that gross fixed capital formation does not significantly contribute on economic growth in the short run, however VAR model in the long run showed that lagged values of GDP, total exports, gross fixed capital formation and had a positive long-run relationship with Nigerian economic growth.

\section{Methodology}

To further establish which factors determine the GFCF for Eastern Cape, the study builds on the model developed by (Langat, 2007; Ugochukwu, and Chinyere, 2013)

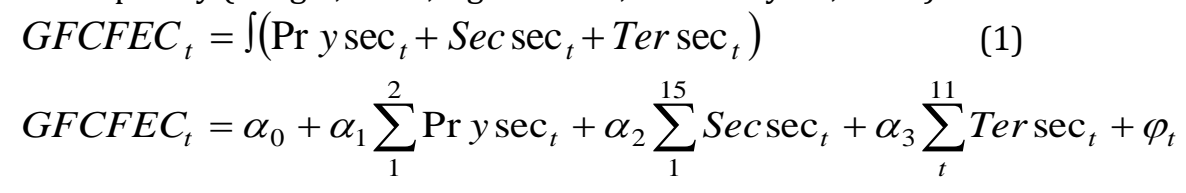

Dynamic transformation of the model is given as:

GFCFEC $_{t}=\alpha_{0}+\alpha_{1}$ GFCFEC $_{t-1}+\alpha_{2} \sum_{1}^{2} \operatorname{Pr} y \sec _{t}+\alpha_{3} \sum_{1}^{15} \operatorname{Secsec}_{t}+\alpha_{4} \sum_{t}^{11} \operatorname{Tersec}_{t}+\varphi_{t}$ 
Where:

Primary sector includes: (1) Agriculture, forestry and fishing, (2) Mining and quarrying.

Secondary sector includes: (1) Manufacturing, (2) Food, beverages and tobacco (3) Textiles, clothing and leather goods (4) Wood, paper, publishing and printing (5) Petroleum products, chemicals, rubber and plastic (6) Other non-metal mineral products (7) Metals, metal products, machinery and equipment (8) Electrical machinery and apparatus (9) Radio, TV, instruments, watches and clocks (10) Transport equipment (11) Furniture and other manufacturing (12) Electricity, gas and water (13) Electricity (14) Water (15) Construction.

Tertiary sector includes: (1) Wholesale and retail trade, catering and accommodation (2) Wholesale and retail trade (3) Catering and accommodation services (4) Transport, storage and communication (5) Transport and storage (6) Communication (7) Finance, insurance, real estate and business services (8) Finance and insurance (9) Business services (10) Community, social and personal services (11) General government.

Estimating Technique: The study followed Pesaran, Shin and Smith in 2001 on time series Auto Regressive Distributed Lag (ARDL) or Bound Testing. In other for the objective of this paper to be achieved, this paper has engaged this estimating technique method to investigate the co-integrating relationship among the independent variables of our study. Due to the good benefits and peculiarities inherent in time series ARDL, time series ARDL would be employed in this study. These features include: It is flexible as there are no restrictions on the possibility of variables to be integrated of the same order. This technique is applicable to variables integrated at both orders I (1) I and (0). Pesaran, Shin and Smith (2001) argue that, ARDL offers dependable and consistent estimates of long-run coefficients provided they are normally distributed asymptotically irrespective of their integration order of either I (1) or I (0). ARDL model despite its endogeneity possibility offers reliable coefficients since it adopts the lags of outcome and independent variables (Pesaran et al., 2001) and again the problem of pre-testing which is a common issue in the conventional cointegration analysis are controlled through the adoption of ARDL.

The Model when transformed to ARDL format gives;

$$
\begin{aligned}
& \Delta \text { GFEC }_{t}=c_{0}+\sum_{j=1}^{n} \beta_{1 j} \Delta G F E C_{t-j}+\sum_{j=1}^{n} \beta_{2 j} \Delta \operatorname{Pr} y \sec _{t-j}+\sum_{j=1}^{n} \beta_{3 j} \Delta \operatorname{Secsec} \sec _{t-j}+\sum_{j=1}^{n} \beta_{4 j} \Delta \operatorname{Tersec}_{t-j} \\
& +\sigma_{1} \text { GFEC }_{t-1}+\sigma_{2} \operatorname{Pr} y \sec _{t-1}+\sigma_{3} \operatorname{Secsec}_{t-1}+\sigma_{4} \text { Ter sec } \sec _{t-1}+U_{t} \ldots \ldots . .(4)
\end{aligned}
$$

In this model $\Delta$ is the first difference operator; $j=$ the number of lags, $c_{0}$ is the model constant, whereas $n$ is the optimal or maximum lag length., $\beta_{1 j-} \beta_{4 j}$ represents the short run coefficients of the respective independent variables and $U_{t}$ is the stochastic / composite error term. $\sigma_{1}-\sigma 4$ denotes the long run coefficients. There are three stages involved to carry out the study regression analysis: (i) we attempt to engage ARDL model in our regression equation model (4) from ARDL environment, we analyze the ordinary least square. (ii) we also analyze long-run relationship in the adoption of bound testing and the null hypothesis, such that; $H_{0}: \sigma_{1}=\sigma_{2}=\sigma_{3}=\sigma_{4}=0$ and the alternative hypothesis; $H_{1}: \sigma_{1} \neq \sigma_{2} \neq \sigma_{3} \neq \sigma_{4} \neq 0$.

Data Source: All the adopted data for primary, and secondary and tertiary section in this study are sourced from Quantec Database 2016. In this section, the factors that determine Eastern Cape GFCF are classified into three categories. These factors are primary, secondary and the tertiary sectors. 


\section{Results}

The long and short run results have indicated that the various sectors are strongly significant. And each sector positive impacts on the Eastern Cape GFCF except the lag of tertiary. A 1\% increase in the primary sector for instance would cause Eastern Cape GFCF to increase by $3.2 \%$ and similar \% change in the secondary sector would cause Eastern Cape GFCF to increase by $16.2 \%$. However, there is a significant impact in the tertiary sector as a $1 \%$ increase in the tertiary sector would cause Eastern Cape GFCF to grow by $81.24 \%$. The rate of the sectors' contribution in the long and short run appears to be similar as the primary, secondary and tertiary sectors impact on the Eastern Cape GFCF by $3.9 \%, 17.8 \%$ and $78.9 \%$ respectively. The result has indicated that the tertiary sector in Eastern Cape contributes significantly to the Eastern Cape GFCF than the other sectors.

Table 1: Showing the series of the dependent variables GFCFEC and the explanatory variables of the primary, secondary and tertiary sector.

ARDL Cointegrating and Long Run Form

Dependent Variable: LOGGFCF

Selected Model: ARDL(1, 1, 1, 2)

Cointegrating Form

\begin{tabular}{lllll}
\hline Variable & Coefficient & Std. Error & t-Statistic & Prob. \\
\hline D(LOGPRIMARY) & 0.032563 & 0.000837 & 38.896703 & 0.0000 \\
D(LOGSECONDARY) & 0.162253 & 0.001180 & 137.453163 & 0.0000 \\
D(LOGTERTIARY) & 0.812440 & 0.001969 & 412.531294 & 0.0000 \\
D(LOGTERTIARY(-1)) & -0.003849 & 0.000802 & -4.796738 & 0.0010 \\
Long Run Coefficients & & & & \\
Variable & Coefficient & Std. Error & t-Statistic & Prob. \\
LOGPRIMARY & 0.038973 & 0.001337 & 29.156355 & 0.0000 \\
LOGSECONDARY & 0.178037 & 0.008710 & 20.441120 & 0.0000 \\
LOGTERTIARY & 0.789570 & 0.009492 & 83.179385 & 0.0000 \\
C & 0.547478 & 0.025756 & 21.256078 & 0.0000 \\
\hline
\end{tabular}

Source Authors' Computation, 2017

Table 2: Error Correction Coefficient

\begin{tabular}{lllll}
\hline Variable & Coefficient & Std. Error & t-Statistic & Prob. \\
\hline ECT(-1) & -0.313845 & 0.028540 & -10.996823 & 0.0000 \\
\hline
\end{tabular}

Source Authors' Computation, 2017

The short and long-run dynamic results in this study's model are examine through the adoption of Error Correction term (ECT). The coefficient of ECT indicates the degree of how slowly or quickly the variables under examination tend to revert to the equilibrium state (i.e., their speed of adjustment). As seen in the table 2 , the sign of the negative coefficient in the ECT shows that there was an earlier existence of disequilibrium in the system, however, the process of adjustment is in the right direction. The value -0.313845 (31.38\%) of ECT depicts the system speed of adjustment moving from the short run deviation to the long run equilibrium and the possibility of improvement in South Africa GFCF. In addition, the ECT which is significant statistically at 1 $\%$, clearly shows that equilibrium in the long run is obtainable. The result supports the finding of Rabbi (2011), which concurred that when Error correction model is strongly significant, it is an indication that there is an existence of a stable long-run relationship, and the steady-state or speed of convergence in the system is predictable. 


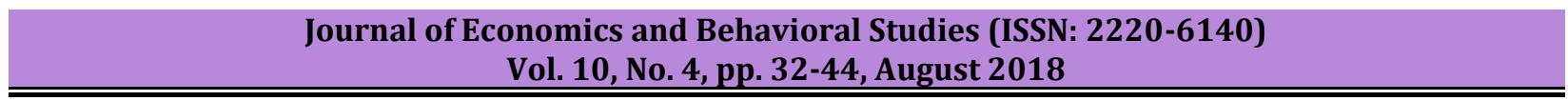

Akaike Information Criteria (top 20 models)

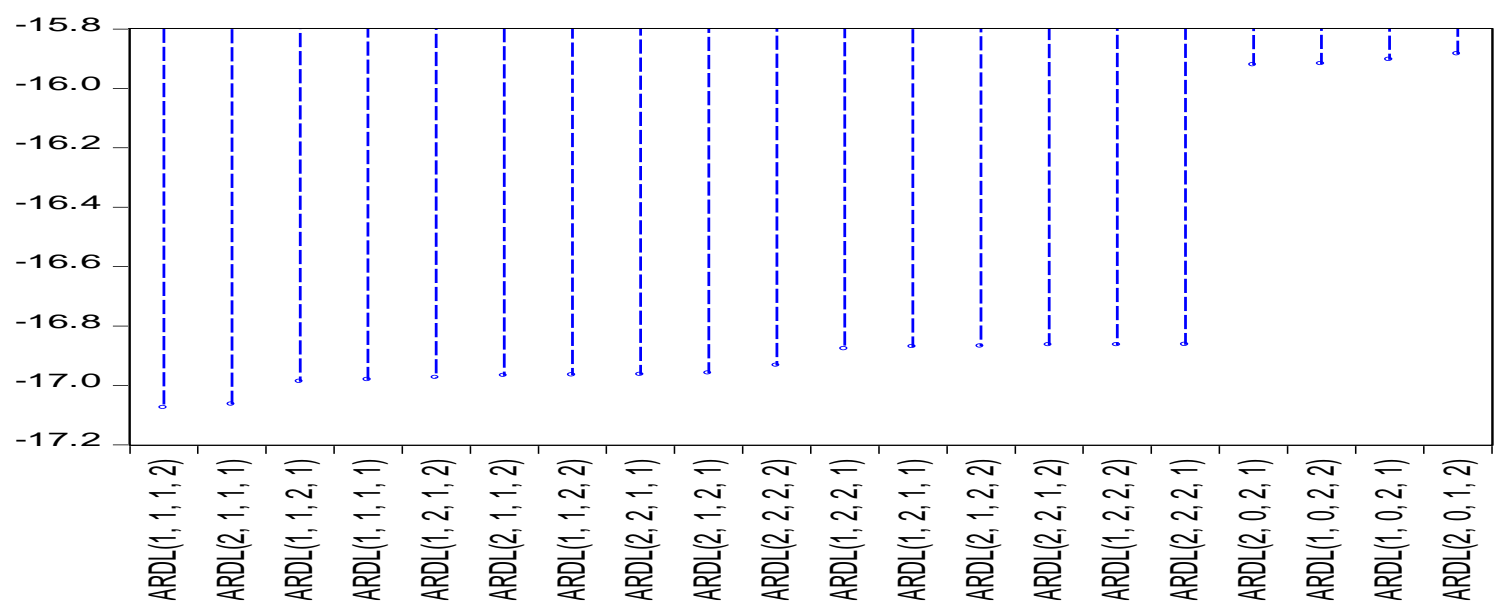

Measuring the Strength of the P-ARDL Regression Model: To establish the strength of the Akaike Information Criterion (AIC) model selection summary over other models (the Schwarz criterion and HannanQuinn criterion) as engaged in our time series ARDL regression model, and to further establish the long and short run relationships in the study model, we have employed criteria graph to examine the top sixteen (16) different time series ARDL models. The common rule of the tomb in the literature on model benchmark analysis indicates that, a lesser value of AIC performs better and is mostly preferred in any given model. It is evidenced from the figure above that the first time series ARDL $(1,0,1,1,1)$ with the value of -14.8 in the model exhibit to be the most expected model above others as it offers the lowest value of the AIC.

Table 3: The Result of ARDL Bound Resting

ARDL Bounds Test

Null Hypothesis: No long-run relationships exist

\begin{tabular}{lll}
\hline Test Statistic & Value & K \\
\hline F-statistic & 7.901343 & 3 \\
Critical Value Bounds & & \\
Significance & I0 Bound & I1 Bound \\
$10 \%$ & 2.37 & 3.2 \\
$5 \%$ & 2.79 & 3.67 \\
$2.5 \%$ & 3.15 & 4.08 \\
$1 \%$ & 3.65 & 4.66
\end{tabular}

Source Authors' Computation, 2017

We again run the bound test to further establish the long relationship between these variables. It is traditional that the value of F- statistics must be higher than both the lower and higher value of the upper bound. As indicated in the table, we can see that the value of 7.9 is higher than 3.65 and 4.66. This further establishes that there exists a long run relationship among the variables in question.

Table 4: Result of Serial and Heteroskedastic Breusch-Godfrey Serial Correlation LM Test:

\begin{tabular}{lllr}
\hline F-statistic & 2.463685 & Prob. F(2,7) & 0.1549 \\
Obs*R-squared & 7.436062 & Prob. Chi-Square(2) & 0.0243
\end{tabular}

Heteroskedasticity Test: Breusch-Pagan-Godfrey

$\begin{array}{llll}\text { F-statistic } & 1.209945 & \text { Prob. F(7,10) } & 0.3789 \\ \text { Obs*R-squared } & 8.254264 & \text { Prob. Chi-Square(7) } & 0.3107 \\ \text { Scaled explained SS } & 0.801949 & \text { Prob. Chi-Square(7) } & 0.9974\end{array}$

Source Authors' Computation, 2017 
Test for heteroskedasticity and serial correlation ware carried out on the regression analysis where it is expected that the variance of the error term is constant for all levels of observation. If this assumption is violated, then heteroskedasticity problem sets in. We use the Breusch- Pagan- Godfrey test to confirm the existence of heteroskedasticity. The rule of thumb here is that three probability values must not be significant. As indicated in our table, this condition was met in our result, meaning that there exists no heteroskedasticity and serial correlation in the model.

Tertiary determinants: The section addresses the tertiary sector of the Eastern Cape gross fixed capital formation made up Wholesale and retail trade, catering and accommodation (TF), (2) Wholesale and retail trade (TF16), (3) Catering and accommodation services (TF17), (4) Transport, storage and communication (TG), (5) Transport and storage (TG18), (6) Communication (TG19), (7) Finance, insurance, real estate and business services (TH), (8) Finance and insurance (TH20), (9) Business services (TH21), (10) Community, social and personal services (TI), (11) General government (TJ). However, determination of lag length is required before going into the regression analysis as this selection would guide in the number of lags appropriate for our model. Based on the result of the on the order selection criteria, lag one most appropriate, hence the adoption of lag one in this estimation and analysis. Endogenous variables: LOGTERT LOGTF, LOGTG, LOGTH, LOGTJ,

Table 5: VAR Lag Order Selection

\begin{tabular}{lllllll}
\hline Lag & Log $\mathbf{L}$ & LR & FPE & AIC & SC & HQ \\
\hline 0 & 240.4683 & NA & $1.18 \mathrm{e}-17$ & -24.78614 & -24.53760 & -24.74408 \\
1 & 361.4154 & $165.5065^{*}$ & $5.44 \mathrm{e}-22^{*}$ & $-34.88583^{*}$ & $-33.39461^{*}$ & $-34.63346^{*}$
\end{tabular}

* indicates lag order selected by the criterion

Table 6: Ordinary Least Square Regression

\begin{tabular}{lclll}
\hline \multicolumn{2}{l}{ Dependent Variable: LOGTERT } & & Prob (F-statistic) & $\mathbf{0 . 0 0 0 0 0 0}$ \\
\hline $\begin{array}{l}\text { Durbin-Watson stat } \\
\text { Selected Model: ARDL(1, 0, 0, 0, 1) }\end{array}$ & 2.308473 & R-squared & 0.999915 \\
Variable & Coefficient & Std. Error & t-Statistic & Prob.* \\
LOGTERT(-1) & 0.260655 & 0.055173 & 4.724362 & 0.0005 \\
LOGTF & -0.080793 & 0.018549 & -4.355703 & 0.0009 \\
LOGTG19 & -0.015985 & 0.017325 & -0.922671 & 0.3744 \\
LOGTH21 & 0.464497 & 0.056932 & 8.158855 & 0.0000 \\
LOGTJ & 0.601723 & 0.036720 & 16.38660 & 0.0000 \\
LOGTJ(-1) & -0.192804 & 0.047380 & -4.069348 & 0.0016 \\
C & 0.225912 & 0.315703 & 0.715586 & 0.4879 \\
\hline
\end{tabular}

SourceAuthors'Computation,2017

Table 7: ARDL Cointegrating and Long Run Result

ARDL Cointegrating and Long Run Form

Dependent Variable: LOGTERT

Selected Model: ARDL(1, 0, 0, 0, 1)

Cointegrating Form

\begin{tabular}{lllll}
\hline Variable & Coefficient & Std. Error & t-Statistic & Prob. \\
\hline D(LOGTF17) & -0.085696 & 0.016859 & -5.083144 & 0.0003 \\
D(LOGTG19) & -0.016363 & 0.017021 & -0.961331 & 0.3554 \\
D(LOGTH21) & 0.486092 & 0.043123 & 11.272240 & 0.0000 \\
D(LOGT) & 0.592014 & 0.026886 & 22.019777 & 0.0000 \\
Long Run Coefficients & & & & \\
Variable & Coefficient & Std. Error & t-Statistic & Prob. \\
LOGTF17 & -0.109276 & 0.019102 & -5.720545 & 0.0001 \\
LOGTG19 & -0.021620 & 0.022987 & -0.940571 & 0.3655 \\
\hline
\end{tabular}




\begin{tabular}{lrlll}
\hline LOGTH21 & 0.628255 & 0.057384 & 10.948277 & 0.0000 \\
LOGTJ & 0.553083 & 0.033334 & 16.591970 & 0.0000 \\
C & 0.305558 & 0.417916 & 0.731146 & 0.4787 \\
Cointeq = LOGTERT $-(-0.1093 *$ LOGTF17_- & $-0.0216 *$ LOGTG19 + 0.6283 & \\
*LOGTH21 + 0.5531*LOGTJ + 0.3056) & & \\
\hline
\end{tabular}

This section showcase the result of the time series ARDL analysis. The variables regressed are Catering and Accommodation (TF17), Communication (TG19), Business services (TH21) and General government (TJ). The selection is appropriate as other variables are submerged into these variables, therefore, to avoid the problem of multicollinearity, the represented variables are selected. Here the long and short run results are submitted and from our estimation, our short and long-run result indicates that Communication (TG19) does not significantly impact on the Eastern Cape tertiary sector. Whereas Catering and Accommodation (TF17), has an inverse relationship both for a long and short-run relationship. However, Business services (TH21) and General government (TJ) positively impact on the Eastern Cape tertiary sector. Meaning that increasing this sector would increase the tertiary sector. It is interesting to note that the combination of some sectors do not necessarily imply compatibility as some cases are in the study.

Table 8: Error Correction Coefficient

\begin{tabular}{lllll}
\hline Variable & Coefficient & Std. Error & t-Statistic & Prob.* \\
\hline ECT $(-1)$ & -0.683068 & 0.090149 & -7.577129 & 0.0000 \\
\hline
\end{tabular}

Source Authors' Computation, 2017

The short and long-run dynamic results in this study's model are examined through the adoption of Error Correction term (ECT). The coefficient of ECT indicates the degree of how slowly or quickly the variables under examination tend to revert to the equilibrium state (i.e., their speed of adjustment). As seen in table 8, the sign of the negative coefficient in the ECT shows that there was an earlier existence of disequilibrium in the system, however, the process of adjustment is in the right direction. The value $-0.6830(68.30 \%)$ of ECT depicts the system speed of adjustment moving from the short run deviation to the long run equilibrium and the possibility of improvement in South Africa GFCF. In addition, the ECT which is significant statistically at 1 $\%$, clearly shows that equilibrium in the long run is obtainable. The result supports the finding of Rabbi (2011), which concurred that when Error correction model is strongly significant, it is an indication that there is an existence of a stable long-run relationship, and the steady-state or speed of convergence in the system is predictable. The model experiences excess height, if $\mathrm{K}>3$. Indicating above average height. The Kurtosis value of 3.8 fits in as it slightly goes above 3 by implication our model is normally distributed. In addition, in this study normality test on the regression analysis further conducted. This is done to control for normal distribution, our expectation based on the existing rule of thumb is that the value for kurtosis should cluster around the Kurtosis of 3.0

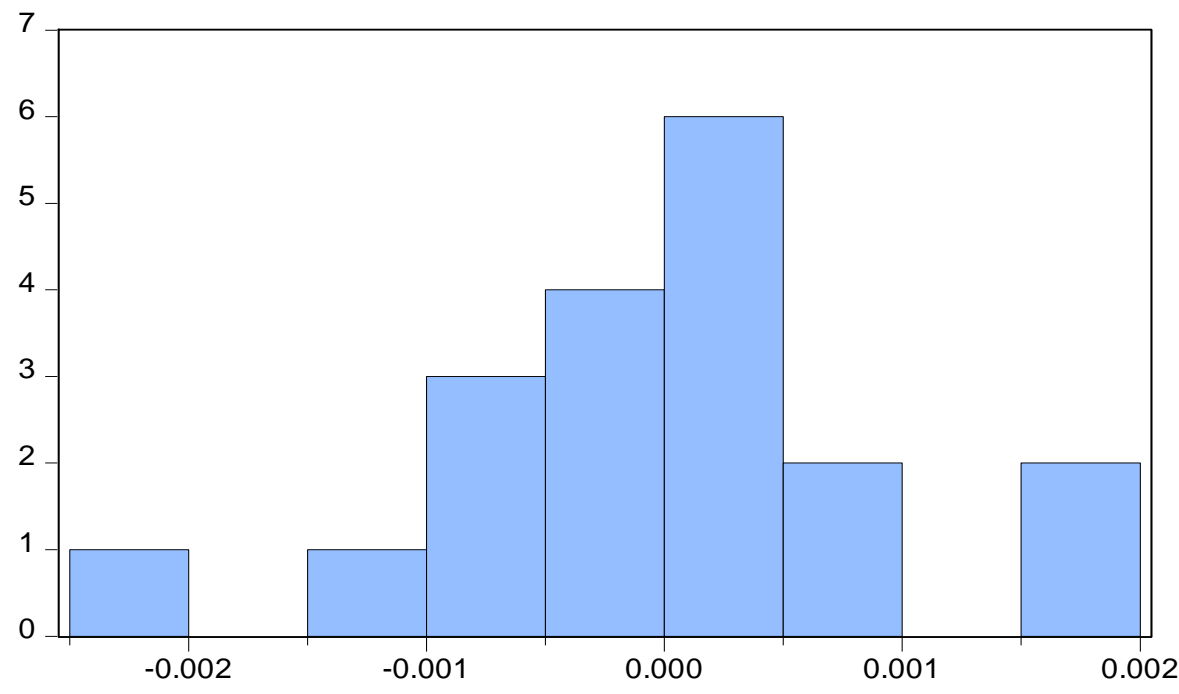

Series: Residuals

Sample 19962014

Observations 19

Mean

Median

$1.46 \mathrm{e}-15$

Maximum

Minimum

Std. Dev.

Skewness

Kurtosis

Jarque-Bera

Probability
0.000164

0.001917

$-0.002496$

0.001004

$-0.253639$

3.833913

0.754253

0.685829 
Jarque-Bera: A further test of normality is from the value of J-Bera which combines both Skewness and Kurtosis. The normal standard or Decision Rule:If $J-B<5.99 \rightarrow$ We do not reject the $H_{o}$ (it shows there is normality). If $J-B>5.99 \rightarrow$ We reject the $H_{\mathrm{o}}$ (i.e. there is no normality). Again, with Jarque Bera Value of 0.68529 , we do not reject $\mathrm{H}_{\mathrm{o}}$, meaning there is normality.

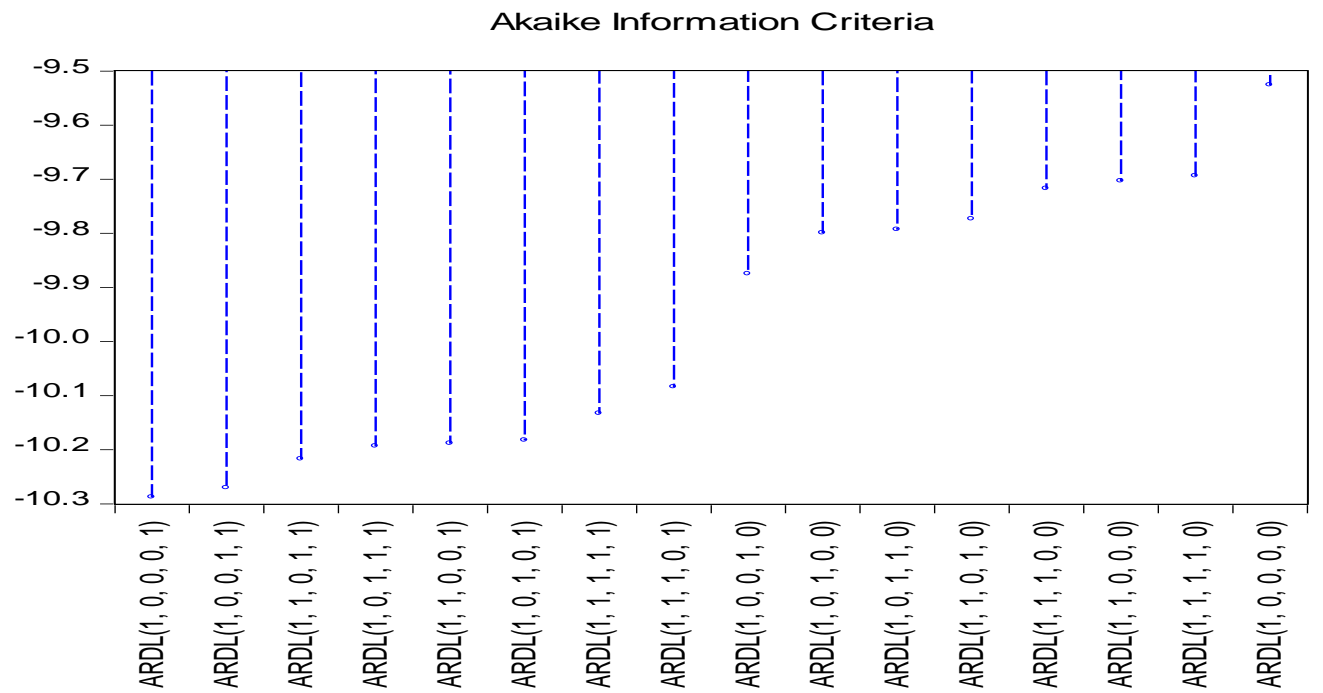

Measuring the Strength of the P-ARDL Regression Model: To establish the strength of the Akaike Information Criterion (AIC) model selection summary over other models (the Schwarz criterion and HannanQuinn criterion) as engaged in our time series ARDL regression model, and to further establish the long and short run relationships in the study model, we have employed criteria graph to examine the top sixteen (16) different time series ARDL models. The common rule of the tomb in the literature on model benchmark analysis indicates that, a lesser value of AIC performs better and is mostly preferred in any given model. It is evidenced from the figure above that the first time series ARDL $(1,0,1,1,1)$ with the value of -14.8 in the model exhibit to be the most expected model above others as it offers the lowest value of the AIC. As indicated in the table, we can see that the value of 11.54376 is higher than 3.29 and 4.37. This further establishes that there exists a long run relationship among the variables in question.

Table 9: ARDL Bound Testing

ARDL Bounds Test

Null Hypothesis: No long-run relationships exist

\begin{tabular}{lll}
\hline Test Statistic & Value & K \\
\hline F-statistic & 11.54376 & 4 \\
Critical Value Bounds & & \\
Significance & I0 Bound & I1 Bound \\
$10 \%$ & 2.2 & 3.09 \\
$5 \%$ & 2.56 & 3.49 \\
$2.5 \%$ & 2.88 & 3.87 \\
$1 \%$ & 3.29 & 4.37 \\
\hline
\end{tabular}

Source Authors' Computation, 2017

This section records the result of serial correlation. The traditional rule guiding the result on serial correlation is that to show that our model is free from serial correlation problem, the F-Statistic and the value of the observed R squared must not be significant. Hence our result adequately passed this test as shown in the table. This section records the result of serial correlation. The traditional rule guiding the result on serial correlation is that to show that our model is free from serial correlation problem, the F-Statistic and the value of the observed R squared must not be significant. 


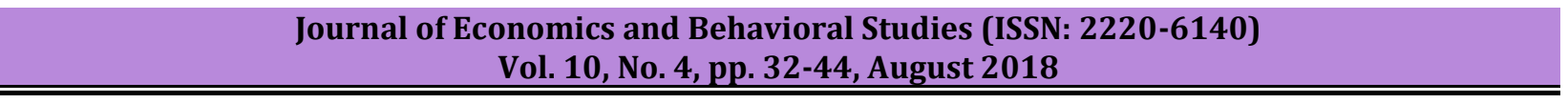

Table 10: Breusch-Godfrey Serial Correlation LM Test

\begin{tabular}{llll}
\hline F-statistic & 1.556527 & Prob. F(2,10) & 0.2579 \\
Obs*R-squared & 4.510622 & Prob. Chi-Square(2) & 0.1048
\end{tabular}

Source Authors' Computation, 2017

\section{Stability Test}

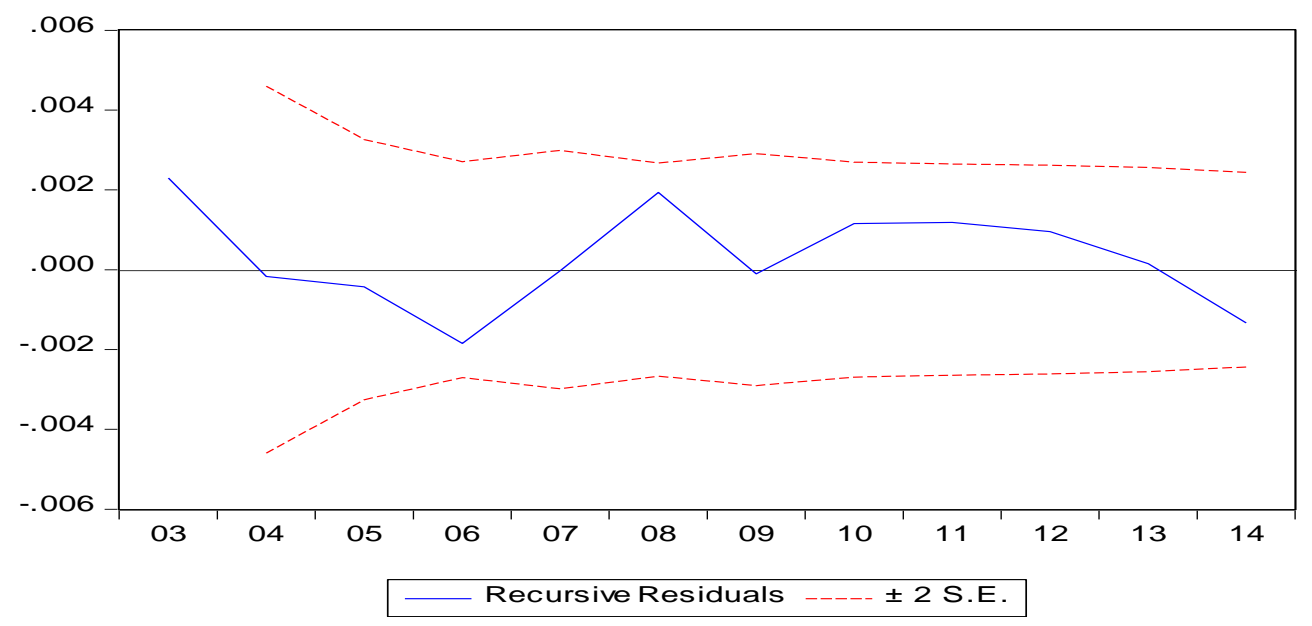

Again, the study conduct stability test on recursive residual using Cusum procedure at $5 \%$ level of significance. The normal tradition of stability of variables in the model entails that the blue line falls within the two red lines, and clearly shown from the regression result, it shows that our result is stable and it further affirms the claim that there is a long run relationship as shown in the figure above. Again, the study further checks the possibility of having short run relationship flowing from the set of the provincial determinants of GFCF in Eastern Cape and Eastern Cape GFCF by adopting the Wald test with a null hypothesis of no short-run co-integration in the model.

Table 11: Wald Test

Wald Test:

Equation: Untitled

\begin{tabular}{|c|c|c|c|}
\hline Test Statistic & Value & Df & Probability \\
\hline F-statistic & 23582.85 & $(6,12)$ & 0.0000 \\
\hline Chi-square & 141497.1 & 6 & 0.0000 \\
\hline \multicolumn{4}{|c|}{ Null Hypothesis Summary: } \\
\hline \multicolumn{2}{|c|}{ Normalized Restriction $(=0)$} & Value & Std. Err. \\
\hline \multicolumn{2}{|c|}{ Catering \& Accommodation } & 0.260655 & 0.055173 \\
\hline \multicolumn{2}{|c|}{ Communication } & -0.080793 & 0.018549 \\
\hline \multicolumn{2}{|c|}{ Business Services } & -0.015985 & 0.017325 \\
\hline \multicolumn{2}{|c|}{ General Government } & 0.464497 & 0.056932 \\
\hline
\end{tabular}

Null Hypothesis: Catering \& Accommodation= Communication=Business Services= General Government. $H_{0}$ : There exists no short-run co-integration for the set of the determinants of GFCF in Eastern Cape and Eastern Cape GFCF. $H_{1}$ : There exists a short run co-integration among the selected set of the provincial GFCF variables and South Africa GFCF determinants of GFCF in Eastern Cape and Eastern Cape GFCF. The Decision rule: Accept null hypothesis $\left(\mathrm{H}_{0}\right)$ when the $\mathrm{P}-$ Value is greater than $5 \%$. Reject null hypothesis $\left(\mathrm{H}_{0}\right)$ when the $\mathrm{P}$-Value is less than $5 \%$. The result indicates that there is an existence of short-run relationship moving from the set of the determinants of GFCF in Eastern Cape and Eastern Cape GFCF at the 1\%P- value. It shows that the study cannot accept the null hypothesis, we therefore reject the null hypothesis and accept the alternative 
hypothesis. Since statistic argues that Eastern Cape contributes 7.5\% of GFCF to South African Economic growth, our result has been able to establish that this contribution is positive and hence the need to increase it in other to improve the growth rate of South African Economic. Time series ARDL is adopted in our estimating technique using augmented Cobb Douglas as our model equation. The study discovers the mixed relationship among the variables under investigation. For policy implication, rather than government activity prevalent in Eastern Cape in the area of grants and financial aids.

Table 12: Short-Run Causality Tests on the series Log of SA GFCF on the Log of MPU, EC, NW and NE

\begin{tabular}{llcl} 
& \multicolumn{1}{l}{ EQUATION: P-ARDL, HO=TF17=TG19=0 } & \\
Statistics & VALUE & DF & PROBABILITY \\
F-statistics & 107.9229 & $(2,12)$ & 0.0000 \\
& EQUATION: P-ARDL, H0=TG19=TJ=0 & \\
Statistics & VALUE & DF & PROBABILITY \\
F-statistics & 46.26115 & $(2,12)$ & 0.0000 \\
& EQUATION: P-ARDL, H0=TG19=TJ=0 & \\
Statistics & VALUE & DF & PROBABILITY \\
F-statistics & 44.31432 & $(2,12)$ & 0.0000 \\
\hline
\end{tabular}

Source Authors' Computation, 2017

Inferences, Comparison with Other Studies: This study carried out an extensive analysis on the effects of various sectors of primary, secondary and tertiary activities on the overall Eastern Cape Province GFCF of South African. Our result clearly shows that all the three sectors of the economy, namely: primary, secondary and tertiary sector have a significant impact on Eastern Cape GFCF. However, the tertiary sector has more impact than other sectors. More particularly, steps have been taken to consider factors that determine the growth of Easter Cape GFCF, and from the result, tertiary sector has the tendency of improving the Eastern Cape GFCF since of all the three sectors, tertiary sector contributes greatly to the tune of $81.24 \%$. This result is supported by the study conducted by Torbira and Ogbulu (2014); Karim, Karim and Ahmad (2010), who found a positive relationship with the tertiary sector of the economy and growth. The positive significant relationship result conforms with the outcome result of Fedderke (2005); Kumo (2012); Nowbutsing (2012) and Bakare (2011). However, our result negates the claim of Kanu and Ozurumba 2014; Torbira and Ogbulu 2014 who found a negative relationship between factors that determine GFCF and GFCF among countries of interest.

\section{Discussion and Conclusion}

This study investigates the nexus among the GFCF of South African Provinces and particularly that of the Eastern Cape and its overall impacts. Data adopted cover a period between 1996 and 2015. The null hypothesis for this study is that there is no significant statistical contribution between Eastern Cape GFCF and the factors that determine it on South African Economic growth. Some of the contributions to the knowledge of the study to the growing literature are that: (1) the study has been able to provide evidence beyond mere statistical evaluation that Eastern Cape contributes significantly to South African Economic growth, however, the extent of its contribution is a function of the factors that determine it. (2) Again, we provide evidence to establish that tertiary sector of the Eastern Cape GFCF contribute more than the addition of both primary and secondary sector put together in the province (3) We also provide evidence to establish that government activity contributes more among the factors that determine the Easter Cape GFCF, there must be a redirection of fund for the development of Primary sectors such as agriculture and mining since this sector contributes only $3.3 \%$ to the overall Easter Cape GFCF. It is interesting to note that the combination of some sectors do not necessarily implies compatibility to enhance the growth of the tertiary sector as some case are in the study.

For instance, Growth is enhanced through the following determinants: Catering and Accommodation (TF17) and not necessarily when Wholesale and retail trade is inclusive; Again, there is a better performance of the GFCF in the tertiary sector with Communication (TG19) than when Transport and storage, are merged together, and finally, Business services (TH21) behaves better with tertiary sector than when it combines with Finance, Insurance and real estate. In the light of the above findings, both sectors that stimulate capital 
formation and those that performed otherwise need policy restructuring to enhance economic growth. Hence, South Africa policymakers must look inward to the splitting of sectors such as Transport and storage to be managed individually rather than being merged together as this would lead to an improvement in productivity. The study is interested in viewing the various sectors of GFCF in Eastern Cape from the perspective of their overall impact on South African Economic growth, and if South Africa as a nation would need to meet her economic development objectives, of great importance is the need for capital formation or capital accumulation otherwise known as physical capital stock.

\section{References}

Adegboyega, B. \& Odusanya, I. (2014). Empirical analysis of trade openness, capital formation, FDI and economic growth: Nigeria experience. The international journal of social science and humanities, 1 , 36-50.

Akinola, G. W. \& Omolade, A. (2013). Savings, Gross Capital Formation and Economic Growth Nexus in Nigeria, IOSR Journal of Economics and Finance (IOSR-JEF), 1(2), 19-25.

Bader, M. \& Malawi, A. I. (2010). The impact of interest rate on investment in Jordan: a cointegration analysis. Journal of King Abdulaziz University: Economics and Administration, 24(1), 199-209.

Bakare, A. S. (2011). A theoretical analysis of capital formation and growth in Nigeria. Far East Journal of Psychology and Business, 3(2), 11-24.

Beddies, C. (1999). Monetary policy and public finances: Inflation targets in a new perspective. International monetary fund (IMF), 46(3).

Fisher, R. (1930). The genetic theory of natural selection. Oxford University Press. Oxford.

Ghura, D. \& Hadji, M. (1996). Growth in Sub-Sahara Africa. Staff paper, the International monetary fund (IMF), 43.

Ghura D. (1997). Private investment and endogenous growth: Evidence from Cameroon. International monetary fund (IMF), Working Paper 97/165.

Jhingan, M. (2003). Macroeconomic theory. New Delhi: Vrinda publications limited.

Jhingan, M. L. (2005). The Economics of Development and Planning, 38th Ed. New Delhi: Virade Publications (P) Ltd, India.

Langat, P. K. (2007). The determinants of fixed capital formation in Kenya. A research paper submitted to the School of Economics, the University of Nairobi in partial fulfilment of the requirements for the degree of Master of Arts in Economics.

Kanu, I. \& Ozurumba, A. (2014). Capital Formation and Economic Growth in Nigeria. Journal of human-social sciences: Economic, 4(4).

Karim, Z. (2010). Monetary policy and firm's investment in Malaysia: A panel evidence. Journal of economics and management, 18(2), 221-253.

Khan, F., Muneer, S. \& Anuar, M. A. (2013). Relationship between Stock Prices and Economic Variables: Sectoral Analysis. Actual Problems of Economics, 5(143), 544-553

Kumo, W. L. (2012). Infrastructure investment and economic growth in South Africa: A Granger causality analysis. African Development Bank Group Working Paper Series, (160).

Malawi, A. (2005). The impact of gross fixed capital formation and money supply on economic activity in Algeria. Mu'tah University. Jordan.

Ncanywa, T. \& Makhenyane, L. (2016). Can investment activities in the form of capital formation influence economic growth in South Africa?

Nowbutsing, B. (2012). Capital formation and economic growth in Mauritius: Does FDI matter? University of Technology. Mauritius.

Muneer, S., Jahanzeb, A. \& Suwandi. (2016). Income diversification and performance: a comparison of commercial and Islamic banks of Pakistan. Abasyn Journal of Social Sciences, Special Issue, 471-485

Pathunia, R. (2013). Linkages between exports, import and capital formation in India. Journal of social sciences, 2.

Perkins, P., Fedderke, J. \& Luiz, M. (2005). An analysis of economic infrastructure investment in South Africa. South African Journal of Economics. 72(2), 211-228.

Pesaran, M. H., Shin, Y. \& Smith, R. J. (2001). Bounds testing approaches to the analysis of level relationships. Journal of applied econometrics, 16(3), 289-326.

Pettinger, T. (2014). Savings ratio in the UK. [Online] www.economicshelp.org [accessed on 28/10/2017]. 


\section{Journal of Economics and Behavioral Studies (ISSN: 2220-6140)}

Vol. 10, No. 4, pp. 32-44, August 2018

Quantec. (2016). Quantec databases for South Africa. Pretoria, South Africa.

Rabbi, F. (2011). Effectiveness of Monetary Policy in Pakistan: Empirical Evidences based on Bound Test Approach.

Rajni, P. (2013). Linkages between export, import and capital formation in India. International Research Journal of Social Sciences, 2(3), 16-19.

Stats, S. A. (2015). www.statssa.gov.za. [Accessed 25/05/2017].

Shuaib, M. \& Dania, E. (2015). Capital formation: Impact on the economic development of Nigeria 1960-2013. European journal of business economics and accountancy, 3(3).

Torbira, L. L. \& Ogbulu, O. M. (2014). Fund Mobilization by Insurance Companies and Fixed Capital Formation: Evidence from the Nigerian Economy. International Journal of Financial Research, 5(2), 69-81.

Ugochukwu, S. \& Chinyere, U. (2013). The impact of capital formation on the growth of the Nigerian economy. Research Journal of finance and accounting, 4(9).

Uremadu, S. (2012\}. The impact of capital structure and liquidity on corporate returns in Nigeria. International journal of academic research in accounting, 2(3). 